\title{
Influence of Nitriding on the Fatigue Behavior and Fracture Micromechanisms of Nodular Cast Iron
}

\author{
R. Konečná, ${ }^{1, \mathrm{a}}$ G. Nicoletto, ${ }^{2, \mathrm{~b}}$ V. Majerová, ${ }^{1}$ and P. Baicchi ${ }^{2}$ \\ ${ }^{1}$ Department of Materials Engineering, University of Žilina, Żilina, Slovakia \\ ${ }^{2}$ Department of Industrial Engineering, University of Parma, Parma, Italy \\ a aradomila.konecna@fstroj.uniza.sk, ${ }^{\mathrm{b}}$ bgianni.nicoletto@unipr.it
}

Surface modification processes are increasingly used to fully exploit material potential in fatigue critical applications because fatigue strength is sensitive to surface conditions. Nitriding is extensively adopted with ferrous materials because it forms a hard and strong surface layer and a system of superficial compressive residual stresses. Fatigue, however, is strongly dependent also on defects and inhomogeneity. When nitriding is applied to nodular cast iron (NCI), the relatively thin hardened layer (about 300 um) contains graphite nodules (diameter of the order of 30 um), casting defects and a heterogeneous matrix structure. The paper presents and discusses the influence of nitriding on the fatigue response and fracture mechanisms of NCI. A ferritic NCI and a synthetic melt with different content of effective ferrite were initially gas-nitrided. Then, (i) structural analysis of nitrided layers, (ii) fatigue testing with rotating bending specimens, and (iii) fatigue fracture surface inspection were performed. Performance and scatter in fatigue performance is discussed by selective inspection of fracture surfaces and identification fracture micromechanisms. A semiempirical model explains observed trends in test results and is used for the process optimization.

Keywords: nodular cast iron, nitriding, fatigue, fracture mechanisms.

Introduction. $\mathrm{NCI}$ is a construction material with a wide range of applications in engineering practice [1]. For fatigue-critical application the surface characteristics of NCI may be modified by thermochemical surface treatments, such as nitriding, with formation of a hard and strong surface layer and of a system of compressive residual stress. In nitriding, $\mathrm{N}$ is diffused into the metal and such diffusion, once individual atoms of $\mathrm{N}$ have penetrated the surface, continues as long as the temperature is high enough, and there is a fresh supply of nascent $\mathrm{N}$ on the surface. A surface exposed to a nitriding medium will generally form two distinct layers. The outside layer is called white (compound) layer and its thickness generally ranges between zero and $25 \mu \mathrm{m}$ (i.e., phases: $\varepsilon-\mathrm{Fe}_{2-3} \mathrm{~N}$ ) [2]. Phase $\gamma^{\prime}-\mathrm{Fe}_{4} \mathrm{~N}$ is known to show a plastic response particularly in comparison with brittle microstructure containing both $\varepsilon+\gamma^{\prime}$ phases. Underneath the white layer there is a diffusion zone (i.e., phase: $\gamma^{\prime}-\mathrm{Fe}_{4} \mathrm{~N}$ ) [2]. The properties of these layers depend on the type of basic material and its original pre-process hardness. NCI is a widely used construction material in the fabrication of severely stressed mechanical parts of complex geometry because it combines a cost-effective casting technology with high fatigue strength [3].

Materials and Experimental Procedures. Two NCI were considered: (i) standard EN-GJS 400 melt with ferritic matrix (see norm EN 1564) and (ii) the synthetic melt C produced with addition of $\mathrm{SiC}$ into the liquid metal with different content of effective ferrite (EF). The chemical composition of both melts was similar to approximately eutectic composition. Two sets of smooth fatigue specimens were prepared from the material under study. Then, one set of specimens of each material was subjected to a nitriding treatment. The patented Nitreg ${ }^{(\mathbb{B}}$ Controlled Potential process was used on GIS 400 , while melt $\mathrm{C}$ was subjected to optimized gas-nitriding treatment. The fatigue curves were obtained on a rotating bending testing machine operating at $50 \mathrm{~Hz}$ with load ratio $R=-1$. The fatigue limit $\sigma_{c}$ was determined according to a reduced staircase method [4]. 
For melt $\mathrm{C}$ only two stress amplitude levels were investigated to assess the fatigue curve trend. The fatigue fracture surfaces were investigated in SEM on selected specimens. The fatigue initiation location and the mechanisms of stable crack propagation were sought. Nitrided specimens tested at the same stress level and showing different fatigue lives were selected to identify possible sources of weakness in case of both types of material.

Structural Characterization and Fatigue Behavior. The structure of GJS 400 was characterized by ferritic matrix with a regular distribution of graphite nodules with size ranging from 15 to $60 \mu \mathrm{m}$. A significant discontinuous network of carbides with microshrinks on the boundaries of eutectic cells was observed, too. The matrix of melt $\mathrm{C}$ was not homogeneous, with significantly different content of $\mathrm{EF}$ in each specimen. The EF content for specimens with almost fully ferritic matrix is from 70 to $86 \%$, for ferritic-pearlitic matrix from 52 to $69 \%$ and for pearlitic-ferritic matrix from 41 to $51 \%$. The graphite nodules were observed in fully or not fully globular shape predominately with size ranging from 30 to $60 \mu \mathrm{m}$ and with small ratio of size ranging from 60 to $120 \mu \mathrm{m}$.

A nitrided layer of both materials is formed by a thin white layer on the surface of specimen, diffusion zone and subdiffusion zones. The white layers were continuous with variable thickness from 10 to $28 \mu \mathrm{m}$ for GJS 400 , respectively from 9 to $33 \mu \mathrm{m}$ for melt $\mathrm{C}$, with local presence of graphite particles. A thicker white layer and diffusion zone were identified in areas where graphite particles were present. In both materials a thin dark layer, which is most probably a carbonitrided layer, in white layer was identified, when a high magnification was applied. The nitrided layer of specimen 3 (GJS 400) was without presence of cracks but in case of specimen 4 (short life, see Fig. 1), short cracks initiated on the surface of specimens in white layer were observed. Therefore, from local structural and EDS analyses it appears that in the specimen 4, in comparison with specimen 3, a high concentration of nitrogen on the ferrite grain boundaries was locally found.

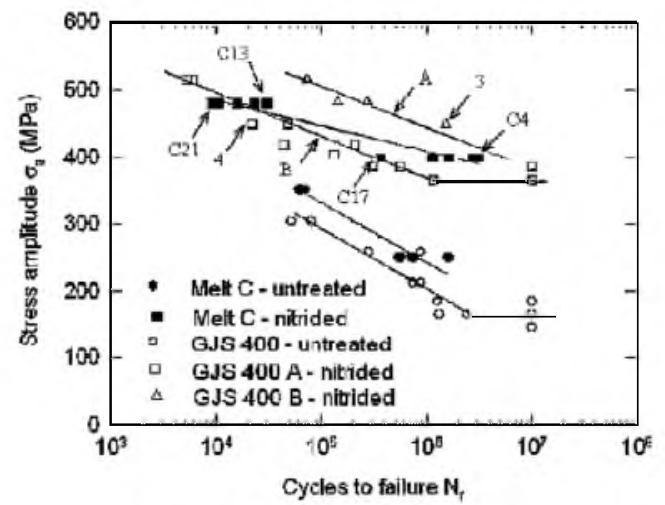

Fig. 1. Fatigue curves.

The fatigue curves of the untreated and nitrided GIS 400 are shown in Fig 1. The fatigue limit is $\sigma_{c}=169 \mathrm{MPa}$ for untreated and $\sigma_{c}=381 \mathrm{MPa}$ for nitrided NCI. The nitriding treatment has provided a very significant improvement of the fatigue response, confirming the range of improvement determined by previous tests on steels [3]. The high fatigue strength is not exclusively due to the formation of the hardened surface layer, because favorable compressive residual stresses are also produced in the surface layers by nitriding. The fatigue life data of the nitrided $\mathrm{NCI}$ are fitted with two parallel fatigue curves, $\mathrm{A}$ and $\mathrm{B}$, because specimens subjected to the same applied stress amplitude showed fatigue lives differing by more than two orders of magnitude. The trend of fatigue curves of melt $C$ (Fig. 1) showed higher number of cycles to failure for the same applied stress amplitude for untreated melt $\mathrm{C}$ because of the lower EF. The fatigue data of untreated and nitrided specimens of melt $\mathrm{C}$ showed no significant dependence of number of cycles to the failure on content of EF. The trend of fatigue curve for nitrided specimens was found in between the two parallel lines characterizing nitrided GJS 400, see Fig. 1. Vickers nanohardness measurements of nitrided layers are presented in Fig. 2. The curves demonstrate longer fatigue life of nitrided specimens having lower DHV values. 
Influence of Nitriding on the Fatigue Behavior...
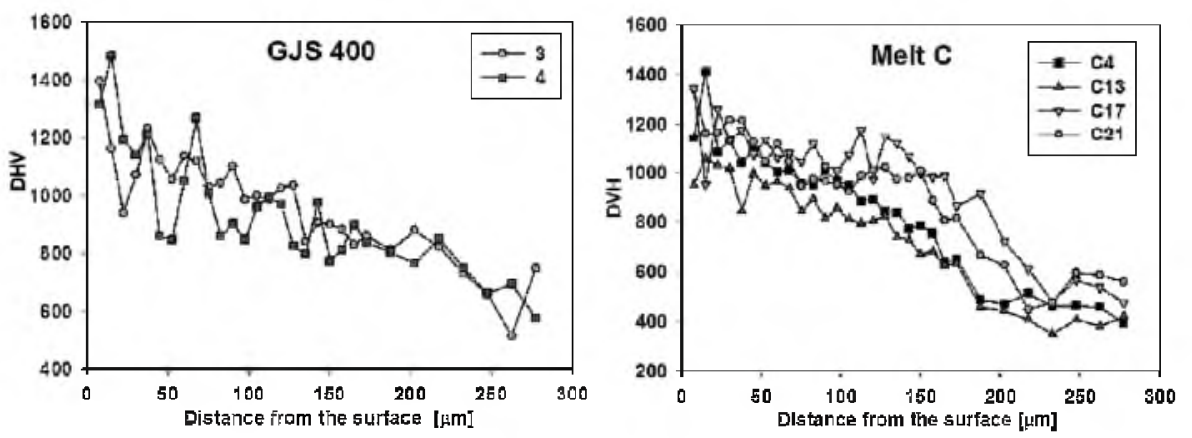

Fig. 2. Nanohardness measurements of the nitrided layer.

Fatigue Fracture Surfaces. From inspection of SEM macrofractographs, multiple sites of fatigue crack initiation were confirmed by the presence of radial stairs on the fracture surfaces. Cracks initiated at casting defects (microshrinks) were found below the white layer, see Fig. 3a, while no crack initiation occurred at internal graphite particles. Initiated cracks then propagated in two directions.

Transcrystalline cleavage characterized the growth through the white layer to the surface (Fig. 3a). The fatigue crack propagation into the material was characterized initially by local plastic deformation of ferrite around graphite nodule. Then crack continued in diffusion and subdiffusion zone first predominantly by intercrystalline decohesion along boundaries of ferrite grains (Fig. 3a) and then by formation of fine striations (Fig. 3b). The presence of striations supports plastic deformation mechanisms of ferrite. In the region of final static failure of both specimens, the crack propagated by transcrystalline ductile fracture of ferrite with dimple morphology.

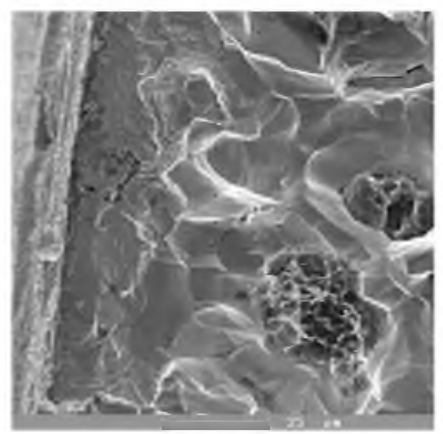

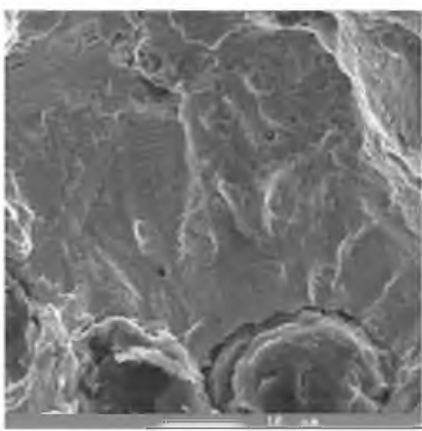

b

Fig. 3. Fatigue fracture surface of nitrided NCI: interface white layer and diffusion zone (a) and fatigue region with striations (b).

Interpretation for Fatigue Life of NCI in the Case of Nitriding. The scheme of Fig. 4 summarizes (i) the current understanding of the parameters involved in controlling fatigue crack initiation and fatigue life of rotating bending fatigue experiments, (ii) the material features affecting fatigue life determined in this study, and (iii) the fatigue crack paths.

Local stresses vary as shown with $\sigma_{b}$, which is fully reversed stress amplitude. It gradually decreases because it is associated to the bending loading from maximum value on the surface. Residual stress distribution $\sigma_{r s}$ is not known exactly but based on evidence in nitrided steels the compressive maximum stress (i.e., 200-300 MPa) is expected near the surface and goes to zero at the case/core interface. This introduces a 
positive mean stress effect that decrease with depth from the surface. Finally, from the nanohardness curves of Fig. 2, the local material strength $\sigma_{h}$ is expected to be maximum near the surface (below the white layer) and to decrease to the core (base) strength.

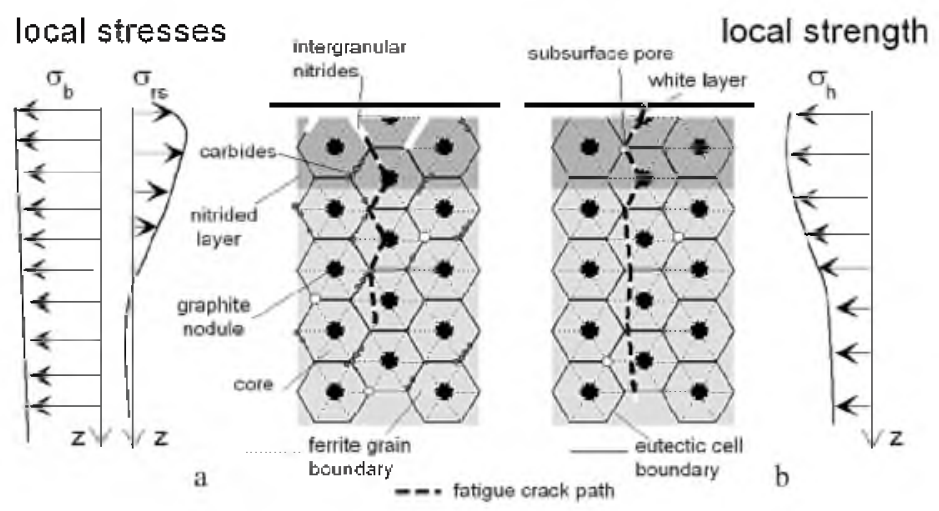

Fig. 4. Scheme of stress and strength profiles in the nitrided NCI and idealized microstructures and crack paths for short fatigue life (a) and long fatigue life (b).

The NCI microstructure is schematically represented by eutectic cells in Fig. 4. Each cell contains one graphite nodule. Cells are divided in several ferrite grains. Figure 4 shows two alternative schemes representative of two mechanisms observed at short and long lives, respectively (specimens 3 and 4 in Fig. 1) in NCI having different content of carbides and microshrinks at eutectic cell boundaries. Upon nitriding, the white layer can be cracked, when the process is not optimized (Fig. 4a), or sound and compact (Fig. 4b). In the first case cracks in the white layer propagate into the base material along the ferrite grain boundaries. When the white layer is sound and compact, crack initiation takes place at microshrinks below the surface at eutectic cell boundaries. Early fatigue crack propagation is intercrystalline in the nitrided layer in both cases. In material with higher content of nitrides at ferrite grain boundaries (specimen 4 ) the stable crack propagation is shorter due to more brittle fracture behavior.

Conclusions. This study has investigated the influence of a nitriding treatment on the material structure and on the fatigue response of nodular cast irons. Tests on smooth specimens of nitrided nodular cast irons demonstrated a significant increase in the long life fatigue strength after nitriding due to the formation of a hardened surface layer and a compressive residual stress system. Nitrided specimens with longer fatigue lives showed $\mathrm{N}$ content without scatter and lower DHV values. Fatigue crack initiation in the nitrided specimens occurred at microshrinks below the white layer. Fatigue cracks propagated in the diffusion and subdiffusion zone along ferrite grain boundaries where the content of $\mathrm{N}$ and the nanohardness DHV were high.

Acknowledgments. This work was done as a part of the SK/IT project No10/NT and a part of the VEGA grant No.1/3194/06. It is also consistent with the objectives of MATMEC, one of Emilia-Romagna newly established regional net-laboratories (http:// www.matmec.it/).

1. J. Davis, Cast Irons/Metallurgy and Properties of Ductile Cast Irons, ASM Specialty Handbook, The Materials Information Society, USA (1996).

2. A. Sinha, Physical Metallurgy Handbook, McGraw-Hill, New York (2003).

3. G. Nicoletto, A. Tucci, and L. Esposito, Wear, 197, 38 (1996).

4. O. Bokůvka, G. Nicoletto, L. Kunz, et al., Low and High Frequency Fatigue Testing. CETRA, EDIS, Žilina (2002).

Received 28. 06. 2007 